\title{
Worldmaking in Sri Lankan Heritage Design: The Case of Travel Writers
}

\author{
By Rodanthi Tzanelli ${ }^{*} \&$ Gauthami Kamalika Jayathilaka ${ }^{ \pm}$
}

This article develops an analytical model to examine how heritage tourism mobilities are designed by travel writers. Using Sri Lanka as an example, we thematise professional activity in heritage tourism through a blend of Margaret Archer's work on reflexivity in late modernity and Keith Hollinshead's 'worldmaking authority/agency' to understand the factors driving tourist design. Our model replaces Jensen's focus on 'design' as a fixed creative property with 'designing' as creativity in motion, here collaborative and solidary, there conflictual and endorsing creative inequalities. Our theoretical blend informs the organisation of Sri Lankan heritage tourist professionals into three active categories: 'communicatives' (with an emphasis on developing closedcommunal solidarity), 'autonomous' (with an emphasis on virtual reconstitutions of community beyond geographical fixity that may support tourist entrepreneurialism), and 'meta-reflexives' (with an emphasis on bringing tourist markets and communities in a dialogue beneficial for the latter) This typology accommodates disparate worldmaking vistas and forms of tourist design agency that then feed back into authorial tourist scripts, promoted by institutions, organisations and even communities. Thus, agency develops both self-reflexively and through negotiations with independently existing authorial forces driving tourist design managed by the nation state and its own biographical records.

Keywords: agency, designing mobilities, reflexivity, heritage tourism, worldmaking

\section{Introduction}

This article develops a new analytical model to examine the ways heritage tourism mobilities are designed by travel writers. Recognising something as 'heritage' partakes of the ways tourism design is understood by travel writing designers and determines the forms of identity such writing produces. Whilst Sri Lanka provides a neat example of the ways a native imagination that was colonised by the West now appears to awaken with the help of its younger female generations of travel writers, the model itself outlines the complexity and ambiguity of this awakening. The model brings together a micro-sociological study of reflexivity (Archer 2012) and a macro-cultural study of tourism 'worldmaking' (Hollinshead 2009). The Sri Lankan case study tests and clarifies

\footnotetext{
*Associate Professor of Cultural Sociology, School of Sociology and Social Policy, Faculty of Social Sciences, University of Leeds, UK.

${ }^{ \pm}$Head, Department of Indigenous Social Sciences, Faculty of Indigenous Social Sciences and Management, Studies, Gampaha Wickramarachchi University of Indigenous Medicine, Sri Lanka.
} 
the new analytical model, by highlighting how foreign/imported systems of governance and structures of belief and action are interlocked into negotiation with native agency in the design of cultural/heritage tourism.

However, it must be stressed that the main objective of our research moves beyond the contextual (Sri Lankan heritage and history) and circumstantial (the feminisation of digital labour, its middle-class nature) variables. Even though an article can only provide limited data ('evidence'), it can develop a workable hypothesis regarding the process of validating one's creative competencies, constraints to social recognition as well as tools and techniques of overcoming them, without becoming a-social agents (i.e., while continuing to belong to a larger whole). The process can be summarised as 'reflexivity', a way of making and remaking our world through internal deliberations of how things are and what is possible to achieve in context. To unpack this, we have selected a 'field' and a theme we delineate as 'Sri Lankan heritage tourism', a social/creative activity we recognise as 'heritage design', and a pool of actors who aspire to become agents ('informants', mainly professional women working in the creative digital sector). In this introduction we walk our readers through these elements, commencing by explaining what tourism means for Sri Lanka, how it is marketed and why and how it interacts with international structures of cultural heritage representation.

Tourism has been considered by scholars and practitioners as a system, an activity, or a profession in various combinations. Greatly affected by economics and psychology, early twentieth century research spoke mostly about mobility motivations, placing an emphasis on the desires of tourists as consumers. This tendency to focus etiologically on individualistic attitudes lingers to date, mainly because of the industry's profit-orientated nature and a misreading of sociological analyses such as that by Georg Simmel, who placed the individual in society, as subjectivist exercises. Critical tourism scholars influenced by interdisciplinary theory have mostly prioritised the study of social inequalities, and when they spoke of tourism as an activity or experience, their subject matter remained the biographical trajectory of the tourist as an ideal type of middle-class modern subject. Some critical tourism theory has taken great strides towards refocusing attention on interplays between structure and agency in the tourismification of places and cultures (Salazar 2009, 2012, Salazar and Graburn 2016), or systems and structures (Korstanje 2016).

Such tensions become even more pronounced in research, in particular tourism niches, which are territories of politicised investigation, such as dark or heritage tourism. The standard definition of 'dark tourism' as human visits to locations 'wholly or partially motivated by the desire for actual or symbolic encounters with death' (Halgreen 2004, p. 149) will not suffice. Using the terms 'cultural' or 'heritage tourism' instead better supports our investigation into the host communities' investment in memory, identity and belonging. Whereas 'heritage' is considered by international NGOs such as UNESCO a universal right to be protected (Labadi 2013), nation-states that emerged from colonisation produce heritage in discursive forms to bolster a sense of identity independently from their former colonisers. 
Sri Lanka's historical background matters in our analysis and we intend to address this as part of our introductory scaffolding to generate connections between indigenous context (results and discussion) and our epistemological proposition (literature review). The Sri Lankan context has been studied as a standard case of colonialism. Sri Lanka's colonial influence begins as early as the sixteenth century, when the country began to be occupied by the Portuguese, Dutch and English respectively from 1505 onwards. For the next 400 years the island was subjected to successive naval powers, which controlled parts or the entire country and radically modified its social and economic structures (Wickramasinghe 2006). Coming in last, the British built the island on native structures as well as the Dutch legacy (Schrikker 2007), so we may conclude that the transformations begun between the sixteenth and the eighteenth centuries under the Portuguese and Dutch gathered momentum during the British rule (Wickramasinghe 2006). The British created a market society spearheaded by the demands of plantation capitalism so that amidst a period of worldwide revolutions and imperial change, along with similar nations in the region, Sri Lanka (then Ceylon), was gradually turned into a modern colonial state in the hands of the British.

In 1815 Sri Lanka was brought under a single English-speaking administration, converted into a unified island polity, from a colonial state to a nation state, forming a boundary-based society (Wickramasinghe 2006). English was gradually embraced as a virtual mother tongue by a section of the multi-ethnic non-European population of Sri Lanka constituting Sinhalese, Tamils, Moors, and the Malays. It became the language of commerce, administration, and secondary and tertiary education (Sivasundaram 2013). The acquisition of English by Sri Lankans from early on provided opportunities for an elite class to form, gradually transforming Sri Lanka from a caste-based to a class-based society. The British colonial rule utilised a range of institutions, such as justice and education, to submerse their colonial subjects in modernity and produce the national elites and leaders of the country, thus consolidating the anglicisation of well-to-do segments of society during the colonial period and its aftermath (Gamage 1997). The main underlying intent had been to create modern colonial subjects who would be efficient and willing servants of the Empire (Wickramasinghe 2006, p. 42, Ashcroft et al. 1989 , p. 4).

At the same time, coloniality influenced cultural production and social formation in the country and ongoing construction and representation of specific spaces and experiences (Hall and Tucker, 2004). It 'set in motion a discursive and intellectual way of thinking, seeing, and writing about the country space as a romanticised and sexualised island... or a lost Eden' (Sivasundaram 2013, p. 14), in that among others islandness and tropicality are two ways of seeing and imagining Sri Lanka (Jazeel 2009, 2013). As an ex-colony Sri Lanka increased in popularity as a favoured tourist destination whereby its places, people, customs, artefacts, arts and crafts, indigenous and colonial heritage and histories were transformed into tourist sites. Western ways of seeing continued and were repeated, reproduced well into independence (gained in 1948) and the advent of institutionalised tourism in the late 1960s, when the first textual/visual tourist 
brochures and promotional materials began to be produced and disseminated (Samaranayake et al. 2013). Tourism motivated by an interest in the history, traditions and consumption of Ceylon tea is a good example that combines aspects of heritage tourism, ecotourism, health tourism and farm or rural tourism (Aslam and Jolliffe 2015). This is particularly significant since tea was popularised, and its traditions introduced to Sri Lanka and developed by the British (Jolliffe 2007). Thus, much of the built heritage remains of Ceylon's colonial tea industry have evolved into heritage accommodations for tourists. Tea heritage tourism also includes tea centres and retail outlets, tea gardens, tea processing factories and landscapes (Aslam and Jolliffe 2015) driven by a nostalgia for the past and a desire on the part of the tourists to experience forgotten cultural landscapes and relive them in the form of tourism (Caton and Santos 2007).

However, in this article we are interested in the ways colonial mentality seeps through the cracks of organised knowledge after the fact, when administrative decolonisation has been completed, and native culture has acquired sovereignty and statist form (Herzfeld 2002). Although such pleasure peripheries managed by free states have gone through centuries of interpreting their place in the world without such external control, they still borrow from their erstwhile control centre's portfolios of development (Said 1978, Alatas 1974). Whereas administrative structures of colonialism and the very economic model of imperialism may be replaced by native nationalism, the overall foreign mentality is difficult to extricate and tends to be reproduced unreflexively in cultural organisation. This produces models of culture - 'knowledge economies', such as particular versions of cultural tourism (Tzanelli 2015). This form of culture sits at intersections between cybernetic (digital design of tourism), ecological (the management of native environments) and biopolitical (the management of national and multiple social identities based on class, gender and so forth) interests (Fuller 2012). At these intersections particular types of humans are designed - by human actors, who imagine themselves as part of communities. Undoubtedly, the professional design of cultural/heritage tourism in terms of visitations to places managed by national power has an economic dimension (Smith et al. 2010). However, economic studies seldom address affiliations between creative agency in heritage design and legacies of cognitive subjection to an external source.

In the following section (literature review), we discuss such links between creative agency and legacy both contextually and analytically so as to highlight that emancipation is always a process of negotiation, as realistically there is no absolute "freedom" in a world not ruled by the state of nature and individual desire. Our model is populated by humans, not abstract models, who act between wisdom, talent and the limitations of knowledge and tools they may possess. Thus "tourism" is a systemic example of our much broader and deeper concerns regarding what makes us mobile humans who create and under what conditions. To do so, we outline our model that combines tourism worldmaking and morphogenesis moving on from there to a discussion with examples of Sri Lankan travel writers and the design process in which they engage. 


\section{Literature Review}

Today these versions are channelled through digital design of tourist destinations, as online marketing has an immediate global reach. Such 'knowledge economies' are armed with labour entertaining varied degrees of visibility in the design of heritage tourism, as its primary role may not be the tourist market, but other projects centring on personal development, employment, or empowerment. Such observations are central in our justification of bringing Archer's thesis in play with Hollinshead's. They highlight how 'worldmaking' in tourism may be less about tourism as such and more about changing social and cultural mores in the touristified country: about heritage as an intergenerational hierarchy of values about place, culture, and nation.

Tourism design often commences with collecting from different individual impressions of a place and its culture during travel, to produce a coherent narrative of it befitting the needs of its mobilities arbitrator: the nation-state and its satellite markets (or, under neoliberal rules, vice versa). As part and parcel of 'doing mobility' in Western ways through marketing that often homogenises diverse impressions, the design of heritage tourism may produce or solidify tourism imaginaries, representational frameworks of place, culture, and history (Salazar and Graburn 2016). Notably, however, this article does not examine the mentalities of professionals, who have set agendas on selling place and culture, but some of their potential 'muses': travel writers, who publish their embodied or digital travels to heritage locations in a professional capacity (i.e., as travel journalists), or not (i.e., as independent travel bloggers).

We argue that in contemporary contexts of cultural production, such as that of Sri Lanka, the politics of Western mobility (Cresswell 2010) and the poetics of imaginative native movement are interlocked in the production of hybrid ontologies of design. It has already been argued by others that in the design of Sri Lanka's heritage tourism, we find colonial echoes (Sivasundaram 2013). But the native sources of the travel imagination, the aforementioned travel writers, are primarily drawn from the new middle classes. For these writers, the colonial past they never experienced slides down their hierarchy of priorities. In modern contexts of mobility questions of power are never two-dimensional, as those who are supposed to be enacting structures of domination (e.g., our travel writers) may be subjected themselves to other structures of inequality, from which they want to escape. To do so, they may endorse market capitalism in the ways they produce their own imaginary frameworks, to acquire a voice. Heritage tourism as national ideology emerges at the nexus of the real interests of the nation state and the subjective interests of those involved in tourism worldmaking that supports the national enterprise, both formally (employed as tourist designers) and laterally (travel journalists and bloggers) (Lukes 1974, pp. 15-25). Heretofore, we redirect Cresswell's (2006) suggestion that mobility has conduits and itineraries, pointing at the complexity of what our travel writers enact and support in their writings as a form of structured agency.

Who are these subjects from which tourism systems borrow to form official tourist imaginaries, even though they may not be working in the travel industry as 
professional designers? How can we write their meaningful biographies, not as a record of individual (affective, political, or otherwise) motivations, but so as to acknowledge their role as paradigmatic subjects, who are recruited, often in unsolicited ways, by those who end up claiming authorship of the scripts of native tourism? Such an endeavour would necessitate a reading of human lives and activities as part and parcel of societal tendencies, shortcomings, or examples of cosmopolitan solidarity. Our task is to exorcise the phantom of psychologistic motivations or over-critical takes on tourism mobilities as extensions of consumerist phantasmagorias.

We suggest a thematization of the profiles of Sri Lankan travel writers through sociologist Margaret Archer's (2012) work on reflexivity in late modernity. This is used to explore professional self-identities as paradigmatic of particular forms of social action (roughly corresponding to Hollinshead's (2009) 'worldmaking agency'), so unhelpful 'psychological' interpretations of catering for tourist mobilities are refuted. Notably, our informant pool suggests that both the profession and the amateur endeavour of travel writing are a femininized territory. Not only is the profession/hobby feminine, but it also lacks access to sources of power and an endorsement of displaying forms of self-guided authorship that deviate from the canon of stereotyped Sri Lankan place and culture. The ways female travel writers respond to this challenge is by consciously conforming to a market agenda, with the occasional deviation, whenever this can pass under the radar of inspection. Based on interdisciplinary explorations of the ways agency emanates from the structures in which individuals are born, grow up and occasionally rebel against, Archer's 'morphogenetic/morphostatic' model provides a starting point for a sociological investigation of human action, intentionality, and empathic connectivity with others in our research context.

Archer's work is placed in an unlikely dialogue with tourism studies scholar, Keith Hollinshead's (2009, Hollinshead et al. 2009). Hollinshead developed a comprehensive framework for understanding the ways tourist professionals and tourists produce 'worlds of tourism': conceptual frames for doing tourism and experiencing destinations. He conceived of 'tourism worldmaking' as an activity emanating not from fixed institutional agendas, but self-standing cultural discourses existing independently and mediated via their structures. Where Archer stands outside tourism theory, Hollinshead tapped into the globalising potential of tourist structures (he calls them 'authority'), noting that the actual job of tourism creativity becomes the job of designers, who act on these structures (he calls that 'agency'). Because worldmaking agency is also in an interplay with national interests and contemporary societal structures on the one hand, and global markets and their labour on the other, the choices of our female travel writers become structured: either they fulfil their parents' expectations as women and professionals, or they endorse the market norms and values to achieve personal independence. The 'writing' of heritage tourism becomes part of a personal project of professional development, under which a critique of 'colonial mentality' may or may not survive, depending on personal beliefs and political inclinations. Hollinshead never examined the socio-biographical specificity of the actual 'tourism worldmakers' (i.e., professionals working in the sector) or their 'muses' 
(our travel writers). Archer provides us with the opportunity to examine how sexism, racism and nationalism discursively shape tourism worldmaking at its grassroots level - and why by simply condemning these writers' choices scholars reproduce these structures of inequality.

The Reflexive Imperative in Late Modernity (2012) is Archer's third volume on 'morphostasis' and 'morphogenesis', two concepts referring to the ways past structural conditions impose themselves on social actors without determining them, before being reproduced/elaborated upon respectively through their actions. Like her mentor, Pierre Bourdieu, Archer is unclear with regards to the consciousness of this reproduction/contestation which Bourdieu (1984) termed 'habitus'. To consider the agency of Sri Lankan tourism professionals as a form of reflexivity we repurpose Archer's model to think about distinctive categories of consciously performed travel writing agency in the organisation of cultural/ heritage tourism. We have the following travel writing 'reflexives' in Sri Lankan tourism:

1. Communicatives, emphasising closed-community solidarity against social diversity, reiterating 'family' norms and values.

2. Autonomous, maintaining less connection to communal roots and emphasising instead virtual reconstitutions of community beyond geographical fixity. They may be internet entrepreneurs, and often willing to stage authenticity in communities, mostly to endorse collective valorisation in the tourist trade.

3. Meta-reflexives, focusing their efforts on bringing tourist markets and communities in a dialogue beneficial for the latter ('entrepreneurial activists').

Archer also identifies a fourth type of reflexivity she terms 'fractured', to explore these mobile professionals who display complete loss of rooting, but we are suspicious of the category's normative underpinnings. Also, Archer places these forms of reflexivity in a temporally progressive schema in human history (from 1 in traditional societies to 4 in contemporary ones), but in our pool of data we find the first three types conterminously intertwined, and enabling different forms of deliberation on the touristic craft, which may even change in the course of engagement with tourist destinations (e.g., communicatives may invest in strengthening community development against tourismification, and metareflexives seek to harmonise the two forces, thus acting as mediators of differences, but it is not unlikely that meta-reflexives will develop into fractured entrepreneurial professionals, if they fail to maintain community collaboration). Hence, the typological schema accommodates disparate worldmaking vistas and shifting forms of tourist and host agency that then feed back into authorial tourist scripts (Hollinshead 2009, Hollinshead et al. 2009), promoted by institutions, organisations and even host communities. Archer's model assumes that mobility and/or loss of rooting are bad things that produce bad agents. At the same time, her work tends to endorse a biopolitical vision of belonging, because it has as its basis family and education variables. A critique of Archer's biopolitics, which asserts 
the unconscious and performative reiteration of national, gendered and class identity of travel writers, sits better with Hollinshead's model. This refutes the idea that the objectives of tourism agents/travel writers will always be determined by their family expectations, while acknowledging that biopolitics can affect the organisation of tourism.

Hollinshead's notion of 'worldmaking' refers to the declarative power of tourism in the construction of places, events, or inheritances. Where, following Archer, we would conclude that tourism has the power to act on social modes of being and thinking, to either transform visions of cultural structure, or reiterate them, Hollinshead believes that it has the power to proclaim visions of culture in forms disseminated via institutions or authoritative agents (i.e., professionals). However, for Hollinshead these visions of culture are not being generated by institutions, instead, they reside in deep-seated discourses, circulating in the cultural field. For Hollinshead (1999, p. 271), tourism as practice does not just mirror 'fixed' worlds, it changes the ways they are understood symbolically and materially, 'by tapping into repositories of situated inheritances and heritages'. Tourism is performative for both professionals and locals, who can modify the scripts of power with their performances. Following Archer's (1998, p. 63) logic, like most social rituals, tourism draws on the 'activities of the long dead', to produce variable versions of material, moral and symbolic change/stasis through living agents - a point also supported by Hollinshead (1999) in his earlier work.

Despite any conceptual and theoretical differences, following both theorists, we can conclude that tourism is not just a way of knowing, but being and becoming via multiple 'conversations' with the self and the 'world'. Another shared tenet in these scholars' work is that the couple performance/re-production (i.e., doing/ catering for tourism), transforms the professional or amateur culture writer into a contributor (structured agent) to real-world changes. Archer can help us to focus on the ways professionals articulate social tendencies through their biographical encounters with reality and Hollinshead to focus specifically on ways imagining and reimagining/designing tourism instils social and political reflexivity ('praxis') in the organisations and communities involved in tourism. For Hollinshead, professionals can generate worlds of tourism by tapping into instillations, repertoires, storylines, or standpoints 'that are important to [a] given or found "authorising" management or mediating agency' (Hollinshead and Suleman 2018, pp. 202-203). Where Hollinshead builds a macro-social scaffolding to consider the role of tourism professionalism, Archer helps us with the micro-social dimensions of ethnographic research into the multiple dynamics of professional agency. For critical ethnographic researchers, accustomed to Hollinshead's more abstract vocabulary of worldmaking, Archer provides an entry point to individual action for or against tourist markets, as she thinks in terms of family or community associations. Also, with Archer's thesis, a critical tourism ethnographer can proceed to examine the ways worldmaking scripts are structured and contested by native worldmakers, who reflect on their own position in the inheritances/heritages with which they grew up. The proof is in the test, which follows a brief presentation of our methodology. 


\section{Methodology}

We discuss Sri Lanka's heritage design upon the consideration of local travel writers belonging to three broad categories of writing and representation contributing to the creation of distinctive versions of the country. Among this cohort are those identified as tourism writers, who produce promotional travel material for commercial magazines, websites and other such material, travel journalists who contribute content to local English newspapers and finally travel bloggers who wield their personal travel narratives via online blogs.

We perform content and discourse analysis of 25 travel narratives published in Explore Sri Lanka and Serendib (inflight magazine of SriLankan Airlines), two widely reputed and distributed commercial magazines within the country. In addition, we mobilise content from three independently maintained but influential travel blog sites: Three Sugars in my Tea, Nadeepaws, and NatnZin. These analyses were supported by in-depth interviews with 17 local travel writers belonging to three broad categories of writing outlined below. Among this cohort of writers interviewed and placed under discussion are seven writers - all directly employed for tourism promotion. The initial six writers had all contributed to the magazines, Explore Sri Lanka, and Serendib. None of them was employed by these magazines at the time of the interviews, and only two were engaged in writing as a career, whereas the others had all moved on into other professions or were unemployed at the time. Five interviews were conducted with journalists, who contribute to local English newspapers. Another five interviews were conducted with independent bloggers, who maintained their own blog sites (two of whom work on a single blog site as a couple: working as the writer and the photographer). The degree of professionalism in the interviewees' engagement with heritage tourism design was intentionally dissociated from their employment, so as to think of designing as a dynamic but also asynchronous process of cocreation of similar conceptions of 'heritage'.

Adopting a design perspective calls for an evaluation of process: the 'how' behind the staging of disparate ideas of culture as heritage. This involves borrowing from the visual arts (visualising heritage via technologies, such as photography and cinema) and embodied travel into sites of visualisation (prospective heritage sites) in styles invoking the situationist movement. Such hybrid genres are constitutive of belonging in a mobile world in which communities are constituted both terrestrially and digitally (Germann Molz 2012). Focusing on designing instead of design highlights the involvement of different native agents in heritage tourism concepts. It is significant, for example, that the contribution of female travel writers to this process is largely downplayed in tourism studies and native work contexts, as gender norms produce heritage; or that these women largely work in the digital labour sector.

At first it seems that these writers engage in acts of 'worldmaking' only as 'captives' of colonial mentality (Alatas 1974): that they are pre-programmed in their gaze or aesthetically conditioned and politically pre-imbued with what is worth seeing and celebrating (Hollinshead et al. 2009). However, we argue that leading to these acts of worldmaking, they also engage in some form of internal 
conversation enabling different forms of projection in relation to tourism. We assert, following Archer (2012), that within a context of late modernity in Sri Lanka there is no direct, well-defined, or clear norm or role to simply internalise through socialisation. Instead, the process is to be reconceptualised as 'relational reflexivity' (Archer 2012). Individuals draw upon their socially determined yet personal powers of reflexivity when it comes to their course of action in relation to the nature and uniqueness of the circumstances they come across (Archer 2012).

Accordingly, we scrutinise the way in which these writers engage in internal conversations constituting dialogues that they exercise inwardly whereby they define and clarify their beliefs, attitudes and goals, and delineate projects built upon their main concerns (Caetano 2015). These writers are reflexive beings who deliberate about their circumstances, determining their own courses of action in society (Archer 2003). However, there is no homogeneity in the way they exercise reflexivity. There is a sense of mental privacy and subjectivity through which each writer surveys and evaluates their external circumstances leading to their actions. Whereas colonial influences may appear in the ways they design tourism in their writings, what takes precedence is the 'here and know' pragmatic circumstances in which they write. This generates a dynamic engagement with the past, which can often be seen as a resource, rather than a value, in a project of escape from other community values that endorse inequalities or unwanted career pathways.

\section{Results and Discussion}

In what follows, we attempt to examine the Sri Lankan travel writers in terms of what is identified as internal conversation at a crucial point: when 'reflexivity' transforms into 'critical engagement' with the material and symbolic conditions and constrictions these travel writers have to overcome and/or negotiate. To equip our research with a sound methodology, we concede that situationism (performing travels to such future or established heritage spots) enables their technological representations/visualisation (Jensen 2014, pp. 28-35), and grants such representations with verisimilitude (alleged 'credibility'). However, it is wrong to assume that the same designers carry the task from start to finish: someone may be commencing the process of imagining place and culture and someone else may be taking over, refining, redefining or even usurping such ideas to systematically trade them as tourism.

\section{Communicative Reflexives}

Many of the professional Sri Lankan travel writers engage in or have engaged in what is identified as communicative reflexivity. However, this reflexive exercise does not necessarily influence the nature and logic of the travel writing they produce. This transition from communicative contexts to professional reflexivity that does not necessarily adhere to family values, has mainly been as they had initially commenced their careers often employed by publishers or as freelance journalists. Communicative reflexives are those that engage in an 
internal deliberative process upon constant external influence and consultation particularly given the nature of Sri Lankan society, where family and kinship ties are strong and stable. For instance, decisions about becoming travel writers have been to them strongly predisposed by both nuclear and extended family.

'Kate' provides a good example of a communicative reflexive whose social environment has effectively influenced her decisions and actions particularly in acquiring her professional travel writing position. Kate expressed her high regard for her new urban middle-class family (Hettige 1996) with the guidance of whom she stated that she had become a travel writer for the reputable magazines Explore Sri Lanka and Serendib. She explained the way in which her mother had encouraged her from a young age to learn English, emphasising its significance for future employability and success. As a young adult, she had left for the US to follow an undergraduate degree in Economics. Another characteristic of communicative reflexives is that they share their concerns with significant others around them and seek to resolve issues often interpersonally. 'Kate' explained that upon returning to Sri Lanka after her undergraduate studies she had sought work opportunities and that it was her mother who had directed her to acquire the travel writer position, while she had been applying for NGOs unsuccessfully (Interview with 'Kate' 2018).

A friend of 'Kate', 'Pricilla', who has worked for the aforementioned magazines also made statements revealing strong and stable relationships with her family. She maintained for instance, that her habit of reading which she had picked up from her family made her a good writer in English. 'Pricilla' explained how she had access to a collection of old English classics that were handed down from her grandfather to her mother and to her. Writing in English certainly affects the ways heritage is communicated to travel magazine readers - it bears the stamp of colonial deliberation. However, priority over such lay influences had an entrenched insecurity regarding what constitutes a 'professional' style of writing. These writers appear not to rely completely on autonomous internal conversations - they are mistrustful about arriving at the right decisions and achieving appropriate actions. 'Pricilla' reflects that she was 'always on edge' on her first few days as a travel writer for the aforementioned most widely distributed and reputed magazines in the country. She would often resort to asking her boss: 'okay I met these people and got these many stories and seem to have covered this much... how do I write this?' (Interview with 'Pricilla' 2018). Thus, evidently, family ties were important in the selection of professional orientation, but guidance in writing was not. 'Pricilla' went on to describe that writing for these magazines often meant perusing older issues and following the established styles of writing adopted by these magazines through time. Whilst her statement suggests a communicative reflexive process it also crucially denotes how this leads to orchestrating and perpetuating a particular national image led by a Western-centric promotional agenda and a tourist gaze shaped by centuries of images. 'Priscilla' further established that writing for commercial travel magazines was a constant effort at exclusively depicting the country in a positive light. This she argued involved a certain kind of language involving 'a lot of unnecessary elaboration...too much detail and kind of make things look very romantic' (Interview with Pricilla 2018). 
Significantly, tourism writers such as 'Pricilla' represented the tea industry and culture of Sri Lanka. The tea heritage is a pivotal selling point within the country's tourism sector initiated by the British in the 1870s, during the colonial era within the historic city of Kandy. Since independence Sri Lanka's tea and its associated attractions have been continuously fostered, combining the national culture and colonial heritage as part of the tourism promotion agenda. Loolecondera located in Hantana, Kandy, is the first tea estate in the country where the industry had been born in 1867 when Sri Lanka was still a British colony under the superintendence of the Scottish planter James Taylor. Currently home to a tea museum, a popular tourism destination, much is written about in travel magazines about this. Loolecondera: The Beginning of an Illustrious Brew and Preserving a 150 Year Legacy Ceylon Tea: The Brew that Put an Island on the Map, Exuberant Ceylon Tea, Ceylon Tea a Brew Loved World Over, Ceylon Tea - Soothing the World and Ceylon Tea Celebrates 145 Years are some of the features that portray this particular tea estate. In each of these the estate is portrayed as being enveloped in history, timeless and unchanged. The writers attempt to instil in the reader a nostalgia for a bygone era as often practiced in the promotion of heritage tourism (Caton and Santos 2007). Thus, the Loolecondera estate is not only depicted as an escape into nature and scenic landscape but also characteristically existing outside of time and space (Jayathilaka, 2019). In an article to which 'Pricilla' contributed we read that visitors, who are interested in the tea production process and the 'history of Ceylon Tea, can visit the Tea Museum in Hantane, Kandy for a glimpse into the past' (Rajapakse and Nanayakkara 2011). The journey and experience suggest that this tea estate is 'timeless'. Hence, these writers are engaged in circulating and perpetuating the foundational tourism imaginaries or assemblages. These established ways of seeing contain messages of colonialism (Said 1978) led by an 'imperialist gaze' grounded on nostalgia, the empire and imperialist myths (Brito-Henriques 2014). These professional writers' representations of places, people, and culture of Sri Lanka as timeless, mysterious, exotic or enchanting follow on from colonial representations and an acquired Western-centric lens of looking at the country. This pattern points to an indeterminate relationship vis-à-vis community values, in that these writers begin to reproduce learned by their middle-class families colonial habits, subjected to the styles of the market, which often reinforces them.

This slow rift between native and market or colonial influences is evident in 'Kate's' and 'Pricilla's' decisions regarding their education or career as writers and major influencers or mentors. 'Pricilla', for instance, further revealed that it was through a friend who worked for the magazines that she had obtained the opportunity to join the organisation. This also brings us to what Archer described as 'contextual continuity' (Archer 2003, p. 185): the close and continuous personal relationships between family members which are then complemented by lasting friendships. Incidentally, this recurs in non-professional travel writing. 'Natalie', 'Anna' and 'Amali' are three interviewed bloggers who demonstrated some of these features and 'Lucy', 'Tania' and 'Irene' were three travel journalists whose statements also confirmed their communicative reflexivity. These examples demonstrate that communicative reflexivity is a co-product of structure and 
agency where, structurally, there is evidence of a context that is continuously accessed by the writers throughout their key transitional points and that agentially, they define their work and successes within their new socio-cultural backgrounds (Archer 2003).

In the Sri Lankan context, communicative reflexivity is supposed to have a resurgent nature, because it allegedly wishes to preserve 'native' structures of thought and 'undo' colonial patterns. This can have diverse results, as often breaking free from colonial customs can be replaced with investing into new forms of international paternalism that bring back imperialist styles of action. Illustrations of this paradox appear in interviews with writers from various other categories of writing apart from tourism writing, where family or friends had paid an active role in their acquiring their travel writer positions. 'Natalie', for instance, explained how she had acquired her passion for travel from her mother who is a journalist and political activist by travelling with her from childhood. She had also been influenced by a friend who worked for an NGO. 'Natalie' stated that with time she had developed an interest in sharing these particular places, people and experiences, and her blog writing was influenced by these travels with her mother and her friends. The activist past of 'Natalie's' family is present in the content of her blogging which also has a strong aesthetic dimension we associate with vacationing and collecting impressions. Given the nature of Sri Lankan society and culture, many of the writers are communicative reflexives influenced by both schooling and work, which already encloses colonial attitudes in its engagement with native heritage. As a result, what emerges as 'heritage tourism' is the legacy of colonial acculturation of the Sri Lankan middle classes into Western patterns of touring the 'native interior'.

\section{Autonomous Reflexives: Metamorphosis to Independent Writers}

Unlike in the previous case, some other interviewed travel writers appeared to be individualistic and independent. 'Zin', who maintains a travel blog with her partner 'Nat', explained how she had struggled to stablish a career as a freelance writer while travelling around Sri Lanka and maintaining her travel blog. She argued: 'at the end of the day you need to do what makes you happy. You can't satisfy everyone around you' (Interview with 'Zin' 2018). Speaking of her education and influences on her writing career 'Zin' explained how, after studying Environmental Studies at the University for two weeks meeting her parents' expectations, she joined a different institute to study a degree in English literature following her own passion. At the time of the interview 'Zin' had left home, started studying English and Sociology and to support herself financially had started working for a clothing brand as a social media executive. Despite her parents' dissatisfaction with her choice her determination to follow her passion to become a blogger had grown stronger. In order to become a travel writer, she had to disengage herself from her collective background, so she moved from her hometown Kandy to the capital Colombo. The dense and continuous network of family and friends has been absent from 'Zin's' background upon leaving her hometown and after having met and made friends with travellers from abroad at a 
backpackers' hostel in Colombo and being familiarised with travel blogging, she had developed her own passion to become a freelance writer and travel blogger. Since then, she had sought opportunities to build a portfolio and develop her writing. Many of the other travel bloggers working for magazines such as those mentioned above and promoting tourism also demonstrated this form of reflexivity. They had decided to resign and step into their own personal writing upon the development of their self-knowledge as well as knowledge about society.

Instead of engaging in writing to promote tourism as in the previous case, autonomous reflexive writers such as 'Zin' move away from representations of places that perpetuate the 'othering' of non-Western, developing countries following a way of seeing by the early colonists during periods of European expansion (Echtner and Prasad 2003, Stone and Nyaupane 2019). Instead, they become independent internet entrepreneurs and write about Sri Lanka in their own way. Provided their self-confidence in their own internal conversations these writers declare themselves to be led by the belief that they, and everyone else, should take personal responsibility for themselves, which is not only demonstrated by the ways that they travel but also their writing. Thus, we argue that they engage in the promotion of what they identify as 'responsible' travel.

For instance, 'Zin' travels with her partner 'Nat' via the often-erratic Sri Lankan public transport in search of the unexplored non-touristic destinations, staying with residents of small communities, thereby experiencing local cultures about which they write stories and share via their online blogs (Jayathilaka 2019). She revealed that they often seek hidden and off-the-beaten-track places to visit and write about and promote how to travel responsibly. They are advocates of community-based travel, where they endeavour to promote small-scale local travel related businesses, such as home-stays and local restaurants. In one of her articles Zin writes:

I often think what I love the most about this island is its people. I'm not trying to romanticize the island...I love it when Ibrahim came five kilometres to find our bus just so he could return my floppy hat and our lens cap. I love it when a thambili [native variety of king coconut] aunty in Tangalle giggles about how Nathan looks like a South Indian actor. I love it when a small family in Nanu Oya welcome us and feed us string-hoppers, and lentils curry even when our stomachs are full (Nathan and Zinara 2018).

This form of writing contrasts with that discussed in the previous case where the natural beauty is exoticized. Another such writer is 'Harriet', described her attitude towards the taming of elephants in Sri Lanka and their exploitation for cultural festivals. Elaborating on an article she had to write for a commercial magazine to promote the Kandy Esala Perahera (religious and cultural procession held every August in the city), Harriet stated how her perspective had changed with time: she was assigned to write about how the elephants are dressed, but she thought that the resulting product was a typically romanticised, glorified representation of the event and objectification of animals. Harriet's perception of elephants shifted after she had learned about harm caused to these animals through 
domestication - so, 'now, I'd rather write about the controversial stuff' (Interview with Harriet 2018).

Upon online publication, writers such as Zin use their blogs to promote themselves and their writing and are commissioned by various businesses such as restaurants, hotels, or guesthouses to experience and write about these places. Foremost, however, they have had to establish themselves as travel bloggers, acquire a substantial following and promote themselves through social media before this occurs. Thus, while they promote distinct ways of travelling, they also earn through these commercial collaborations and social media, making them more entrepreneurial than the previously discussed group.

\section{Meta-Reflexive Travel Bloggers}

Many of the investigated travel writers have engaged in some form of autonomous reflexivity particularly during their transformation from professional tourism writers or journalists to independent travel bloggers. These bloggers were also seen to engage in a great deal of meta-reflexivity. The meta-reflexive writers appeared to share 'contextual discontinuity' with the 'autonomous reflexives' (Archer 2003, p. 258). Above all, they appeared not to be firmly rooted in a single context, as made evident through their extensive travels to remote, far away locations in the country. At the same time, the accounts of their experiences seem to contain uniform critiques of society as they appeared to be preoccupied especially with distributive social injustice: they are deeply concerned for the oppressed and the deprived.

'Natalie', one of the travel bloggers, provides a good example of this form of reflexivity. Employed as a content writer for an international organisation, 'Natalie' travels for pleasure, and had just begun blogging about her travels and experiences. On the one hand, she rebuked published content of mainstream tourism which she argued was commercially driven working solely to accentuate the 'the nicer side of Sri Lanka' (Interview with 'Natalie' 2018) and identified this as merely an effort to attract international tourists, gain profit and earn tourism revenue. Claiming that she does not want to write for magazines such as Explore Sri Lanka, Natalie asserted her disregard for the 'one-sided' representations such magazines offered. Instead, through her writing 'Natalie' strives to convey experiences of a more independent, 'wholesome' nature with no time limitations to explore, deadlines or editorial requirements set by a certain magazine or employer. Natalie explained why this form of travelling is more enriching than that of tourism writers when they are commissioned to write about a place:

It's two different areas of writing I guess; I don't like this resort type of thing. I tried it once. I went to like a posh place like for Rs. 30,000 a night or whatever and people don't even look at you. But I've stayed at gewal [houses] in a village in Matale [small town in centra province] where there was no place to stay, no B\&Bs even you know, and we slept on the floor, we ate what they gave, and we got to give them some money. So that's the kind of traveller that I am. I have a friend too she does beautiful pieces about the real problems at the ground level of Sri Lanka, and for me, that is the ideal type of travelling (Interview with 'Natalie' 2018). 
Natalie and the other travel bloggers engage regularly in 'budget travelling' during their spare time not only to learn but also present a more 'authentic' picture of Sri Lankan life, culture, and traditions. One criterion through which these Sri Lankan travel writers define authenticity is by identifying places, locations, and people 'untouched' and 'unspoiled' by tourism often in rural, but nonetheless touristic regions (Noy 2004, p. 85). In other words, the less travelled place and the more difficult path is often associated with being a wholesome experience with a degree of authenticity. In one of her blog articles about a tea estate in the hidden corner of the historic city of Kandy, 'Amalie', another blogger, writes:

We've felt the distance of the journey, just how long the road is from the town, and when the people begin to tell us of all the hardships they've faced, it makes the journey seem longer. The bright lights of Kandy and Hantana light up around the mountain, so high up they seem to ring the peak, yet those living so close to the summit have a different kind of story to tell (De Sayrah 2015).

The last phrase demonstrates the element of authenticity and sincerity the travel bloggers endeavour to bring out through their writing. Natalie stated that opting to stay at small-scale guest houses and homestays also benefits rural communities and help community-based businesses by offering advice on marketing, setting up websites or social media profiles.

These actions and perceptions of the five bloggers interviewed, also point in the direction of volunteer tourism as its ideals are based on making a positive contribution to the social, natural and economic environment of places they travel to, where both the volunteer and the host community benefit from the experience (Ooi and Laing 2010). As such, these are some of the ways in which the bloggers attempt to escape the passivity and commercialism of tourism and seek authenticity (Azariah 2012, Hulme and Youngs 2002). On the one hand, what 'Natalie' and the four other bloggers seek is holistic and demonstrative of meta-reflexivity: a life wholly aligned as an expression of their ideal (Archer 2003, p. 259). On the other, these alternative ways of experiencing the country derive from pre-existing Western concepts such as 'backpacking' 'pro-poor tourism', 'volunteer tourism' or 'community development'. What they adopt are these already stamped Western discourses about tourism, humanity, social change or development, and blogging the tool with which they raise their arguments - points to the westernisation of heritage design.

Also, exemplary of 'Natalie's' meta-reflexive thinking is how her travel narratives tap into some grave social issues within the tea estate sector of Sri Lanka. Whist writing about her travels to the tea growing regions, she portrays social issues such as poverty, poor health and inaccessibility to housing, healthcare, or education by the tea estate workers. She also focuses on some of the persisting gender inequalities whereby women are compelled to work more both in terms of time and volume but denied adequate facilities and the right to reproduction, leadership even at the grass-roots level in an entirely patriarchal plantation social structure. Sri Lanka's 'few major cities, including Colombo' is evolving rapidly, she says. 'We have roads and fancy buildings and education and jobs and houses', 
but not many of these " "evolutions" have graced the lives of poor people (NadeePaws 2015).

'Zin', who was discussed as an autonomous reflexive writer also demonstrates features of meta-reflexive thinking upon functioning as a traveller and blogger. Like 'Natalie', 'Zin' and her partner also travel to remote places in Sri Lanka, usually on impulse with little planning or prior organising, using public transport and community-based, low-budget accommodation. While writing about the beauty of these destinations they frequent, they also feel that it is their responsibility to protect these places, help the host communities and ensure they share the message of sustainability amongst their readers the result of which is their travel blog NatnZin. Nat and Zin explained that through their blog, they also endeavour to promote a 'different kind of travel' (Interview with 'Nat' and 'Zin' 2018). As part of this agenda the duo of bloggers focus on some of the social, environmental, and social costs to tourism. For instance, through their blog post Nine Reasons Why We Dislike Sri Lanka's South Coast the duo portray photographs of litterstrewn roadsides inclusive of non-degradable plastic waste. Claiming that the tourism industry is 'taking over the island as never before' (Nathan and Zinara 2017), they also emphasise issues such as coastal erosion:

What might have opened up the tourism industry in the South Coast? The beaches. Those sandy far-stretched beaches once existed. Now, there's only a little of it. Kudos, humans, you've killed it. There's coastal erosion...Some parts have become narrower than ever that in some years, the waves may wash you over as you're sitting in a Matara-Weligama private bus (Nathan and Zinara 2017).

Through the cases thus far discussed we attempted to examine the way in which the local Sri Lankan travel writers exercise reflexivity through internal conversation, a process that negotiates the effects of structure upon agency. More elaborately, reflexivity was examined as an internal dialogue, which actuates the causal powers of structures where writers project their actions based on the articulation between personal concerns and the conditions that make it possible to accomplish them (Caetano 2015). As posited by Archer, such facilitation relies on agents wielding their personal authority 'to formulate projects and to monitor both self and society in the pursuit of their designs' (Archer 2003, p. 298). We argue therefore, that all these writers are seen as capable of this. The final type of reflexivity that Archer discusses, the "fractured reflexive" thinkers whose powers of reflexivity have been suspended and therefore no longer engage subjectively with the objective environments they encounter were not among the writers of this study.

\section{Conclusion}

In this article we have focused on the designing rather than design of heritage tourism mobilities in Sri Lanka. In more general terms, our model replaces Jensen's (2014) focus on 'design' as a fixed creative property with designing as creativity in motion, here collaborative and solidary, there conflictual and endorsing creative 
inequalities. To consider design in motion, we developed a transferrable reflexive methodological framework of tourism worldmaking as a dynamic process of cocreation and/or asynchronous but progressive creation of similar conceptions of 'heritage'. We thus explored the promotional work of Sri Lankan travel writers to demonstrate the complexity and ambiguity of designing tourism imaginaries.

Through in-depth investigation of interviews and published resources, we have concluded that the social identity of Sri Lankan travel writing is defined at the intersection of class and gender, rather than ethnic specificity exclusively. Whilst certain visions/versions of Sri Lanka derive from cultural discourses mediated through structures that exist independently of the writers, they are part of a reflexive process modulating the writers' 'conversations' with the self and the world. Tourism writers who engage in a communicative reflexive process reiterate 'family' norms and values. In consultation with and help from family and friends, they settle into their professional travel writing roles and often comprehend Sri Lanka and its heritage as a lifeworld founded on Western structures of beliefs. When these writers move along in their careers and gradually develop selfknowledge, they engage in autonomous reflexivity, often becoming internet entrepreneurs and engaging in travel writing to raise awareness about the various conditions of places and people that tourism often exoticizes and romanticises. Meta-reflexive travel writers become entrepreneurial activists aiming to bring tourist markets and communities in a dialogue beneficial for the latter.

Archer's generic focus on the power of family inheritances over individual choice and Hollinshead's notion of worldmaking as an abstracted multimodal force, here espousing structural integration, there agential forms of mobilities design, transform into blends of other and self-directed action. By this we point to the conscious engineering of national heritage as a progressive motion to the future. This 'motion'produces a version of modern human, who is capable of modulating their biological and ecological interests via a combination of cybernetic routes and roots (Fuller 2012): a meta-traveller into one's interior of sorts.

\section{References}

Alatas SF (1974) The Captive Mind and creative development. International Social Science Journal 36(4): 691-699.

Archer MS (1998) Realism and morphogenesis. In MS Archer, R Bhaskar, A Collier, T Lawson, A Norrie (eds.), Critical Realism, 356-381. London: Routledge.

Archer MS (2003) Structure, agency, and the internal conversation. Cambridge: Cambridge University Press.

Archer MS (2012) The reflexive imperative in late modernity. Cambridge University Press.

Ashcroft B, Griffiths G, Tiffin H (1989) The Empire writes back. London: Routledge.

Aslam MSM, Jolliffe L (2015) Repurposing colonial tea heritage through historic lodging. Journal of Heritage Tourism 10(2): 111-128.

Azariah DR (2012) When travel meets tourism: tracing discourse in Tony Wheeler's blog. Critical Studies in Media Communication 29(4): 275-291.

Bourdieu P (1984) Distinction. Cambridge: Harvard University Press. 
Brito-Henriques E (2014) Visual tourism and post-colonialism: imaginative geographies of Africa in a Portuguese travel magazine. Journal of Tourism and Cultural Change 12(4): 320-334.

Caetano A (2015) Defining personal reflexivity: a critical reading of Archer's approach. European Journal of Social Theory 18(1): 60-75.

Caton K, Santos CA (2007) Heritage tourism on Route 66: deconstructing nostalgia. Journal of Travel Research 45(4): 371-386.

Cresswell T (2010) Towards a politics of mobility. Environment and Planning D 28(1): $17-31$.

De Sayrah A (2015) Illustrated travel diary: the Hill Country. Three sugars in my tea. Retrieved from: https://amaliniii.wordpress.com/2015/08/20/illustrated-travel-diaryhill-country/. [Accessed 24 January 2021]

Echtner CM, Prasad P (2003) The context of third world tourism marketing. Annals of Tourism Research 30(3): 660-682.

Fuller S (2012) The art of being human: a project for general philosophy of science. Journal of General Philosophy of Science 43(1): 113-123.

Gamage S (1997) Post-independent political conflicts in Sri Lanka: elites, ethnicity, and class contradictions. South Asia: Journal of South Asian Studies 20(sup001): 359-395.

Germann Molz J (2012) Travel connections: tourism, technology and togetherness in a mobile world. Abingdon: Routledge.

Halgreen T (2004) Tourists in the concrete desert. In M Sheller, J Urry (eds.), Tourism Mobilities, 143-154. London: Routledge

Hall M, Tucker H (2004) Tourism and postcolonialism: an introduction. In M Hall, H Tucker (eds.), Tourism and Postcolonialism, 1-24. London: Routledge.

Herzfeld M (2002) The absence presence: discourses of crypto-colonialism. The South Atlantic Quarterly 101(4): 899-926.

Hettige ST (1996) Introduction: youth, nation state and globalisation. In ST Hettige (ed.), Globalisation, Social Change and Youth, 1-10. University of Colombo: Bangladesh German Cultural Institute, and Centre for Anthropological and Sociological Studies.

Hollinshead K (1999) Tourism as public culture: Horne's ideological commentary on the legerdemain of tourism. International Journal of Tourism Research 1(4): 267-292.

Hollinshead K (2009) The 'worldmaking' prodigy of tourism: The reach and power of tourism in the dynamics of change and transformation. Tourism Analysis 14(1): 139152.

Hollinshead K, Suleman R (2018) The everyday instillations of worldmaking: new vistas of understanding on the declarative reach of tourism. Tourism Analysis 23(2): 201213.

Hollinshead K, Ateljevic I, Ali N (2009) Worldmaking agency-worldmaking authority: the sovereign constitutive role of tourism. Tourism Geographies 11(4): 427-443.

Hulme P, Youngs T (2002) The Cambridge companion to travel writing. Cambridge: Cambridge University Press.

Jayathilaka GK (2019) The worldmaking role of Sri Lankan travel writers: negotiating structure and agency in the study of travel representations. Unpublished Doctoral Dissertation. Leeds, UK: University of Leeds.

Jazeel T (2009) Reading the geography of Sri Lankan island-ness: colonial repetitions, postcolonial possibilities. Contemporary South Asia 17(4): 399-414.

Jazeel T (2013) Dissimulated landscapes: postcolonial method and the politics of space in Southern Sri Lanka. Environment and Planning D: Society and Space 31(1): 61-79.

Jensen O (2014) Designing mobilities. Aalborg: Aalborg University Press.

Jolliffe L (2007) Tea and tourism. Bristol: Channel View Publications.

Korstanje ME (2016) The rise of thana-capitalism and tourism. Abingdon: Routledge. 
Vol. 8, No. $4 \quad$ Tzanelli \& Jayathilaka: Worldmaking in Sri Lankan Heritage Design...

Labadi S (2013) UNESCO, cultural heritage, and outstanding universal value. Lanham: Altamira Press.

Lukes S (1974) Power. London: Macmillan.

NadeePaws (2015) The mountain people. Retrieved from: https://nadeepaws.wordpress. com/2015/04/29/the-mountain-people/. [Accessed 25 January 2021]

Nathan and Zinara (2017) Nine reasons why we dislike Sri Lanka's South Coast. Retrieved from: https://natnzin.com/2017/09/10/mass-tourism-mirissa/. [Accessed 25 January 2021]

Nathan and Zinara (2018) What do travelers love the most about Sri Lanka? Retrieved from: https://natnzin.com/2018/02/15/travelers-love-sri-lanka/. [Accessed 27 August 2021]

Noy C (2004) This trip really changed me: backpackers' narratives of self-change. Annals of Tourism Research 31(1): 78-102.

Ooi N, Laing JH (2010) Backpacker tourism: sustainable and purposeful? Investigating the overlap between backpacker tourism and volunteer tourism motivations. Journal of Sustainable Tourism 18(2): 191-206.

Rajapakse C, Nanayakkara P (2011) Ceylon tea: soothing the world. Serendib.

Said EW (1978) Orientalism. London: Penguin.

Salazar NB (2009) Imaged or imagined? Cultural representations and the 'tourismification' of peoples and places. Cashiers d'Etudes Africaines 49(1-2): 49-71.

Salazar NB (2012) Tourism imaginaries: a conceptual approach. Annals of Tourism Research 39(2): 863-882.

Salazar NB, Graburn NHH (2016) Towards an anthropology of tourism imaginaries. In NB Salazar, NHH Graburn (eds.), Tourism Imaginaries, 1-30. Oxford: Berghahn.

Samaranayake HMS, Lantra N, Jayawardena C (2013) Forty-six years of organised tourism in Sri Lanka (1966-2012). Worldwide Hospitality and Tourism Themes 5(5): 423-441.

Schrikker A (2007) Dutch and British colonial intervention in Sri Lanka, 1780-1815: expansion and reform. Leiden: Brill.

Sivasundaram S (2013) Islanded. Chicago: University of Chicago Press.

Smith G, Messenger P, Soderland H (2010) Heritage values in contemporary society. Walnut Creek: West Coast Press.

Stone LS, Nyaupane GP (2019) The tourist gaze: Domestic versus international tourists. Journal of Travel Research 58(5): 877-891.

Tzanelli R (2015) Mobility, modernity and the slum: the real and virtual journeys of Slumdog Millionaire. London: Routledge.

Wickramasinghe N (2006) Sri Lanka in the modern age. University of Hawaii Press. 